\title{
Factors affecting the implementation of the Minimum Initial Service Package (MISP) for reproductive health during crisis: the case of Eritrean refugees in northern Ethiopia
}

Alemayehu Bayray Kahsay ( $\nabla$ alemayehub35@gmail.com )

Mekelle University https://orcid.org/0000-0002-5608-5790

Alemshet Teshale Haftu

Amhara National Regional Health Bureau

Afewerki Tesfahunegn Nigusse

Mekelle University

Research

Keywords: MISP, RH, Eritrean Refugee camp, Ethiopia

Posted Date: March 5th, 2020

DOI: https://doi.org/10.21203/rs.3.rs-16079/v1

License: (c) (1) This work is licensed under a Creative Commons Attribution 4.0 International License.

Read Full License 


\section{Abstract}

Background: The Minimum Initial Service Package (MISP) is a series of crucial actions required to respond to reproductive health needs at the onset of every humanitarian crisis. Moreover, MISP is a coordinated priority activity to prevent and manage the consequences of sexual violence; prevent excess maternal and newborn morbidity and mortality; reduce HIV transmission; and plan for comprehensive RH services beginning in the early days and weeks of an emergency. During conflicts, natural disasters and public health emergencies, sexual and reproductive health needs are often overlooked. Women and girls may lose access to family planning services, exposing them to unintended pregnancy in dangerous conditions. Women and girls also become more vulnerable to sexual violence, exploitation and HIV infection. In this article we document the practices and factors associated with availability and implementation of services as measured by the MISP for reproductive health in the Eritrean refugee camp, Northwestern zone of Tigray, Ethiopia.

Methods: we conducted an institution based cross sectional study from October 07- 30, 2019 among female reproductive age groups (15-49yrs) who arrived and lived in the refugee camp from June 01 to October 07,2019 . A systematic random sampling method was applied to recruit 422 participants. We collected the data through face-to-face interview using a structured questionnaire. Binary Logistic regression was applied to assess factors associated with MISP implementation.

Results: About $38 \%$ of the refugees utilized Minimum Initial Service Package of reproductive health during their stay in the camp. Factors like age of $15-24$ years [AOR $=0.38(95 \% \mathrm{Cl}, 0.20-0.73)$ ], being rural residents in home country $[A O R=0.53(95 \% \mathrm{Cl}, 0.34-0.83]$, short time length of stay in the refugee camp [AOR $=0.56(95 \% \mathrm{Cl}, 0.33-0.95)]$ were negative predictors, while previous exposure to health information[ $\mathrm{AOR}=2.24(95 \% \mathrm{Cl} 1.44-3.48)$ ] was a positive predictor of MISP services utilization among the refugees in the reproductive age.

Conclusion: The MISP of reproductive health utilization in the refugee camp is relatively high . Previous information on reproductive health helped the refugees in utilizing the service, while a short stay in the refugee camp, being rural residents in their home country and being young age were barriers to utilization of MISP of RH. Strengthening and introducing sexual and reproductive health services for the youth during early crisis would prevent morbidity in refugees. Key words: MISP, RH, Eritrean Refugee camp, Ethiopia

\section{Introduction}

Refugees are those who are uprooted from their homes when fleeing danger or persecution and who receive special status in order to be given asylum in a host country(1). Women and girls are affected significantly in both sudden and slow-onset humanitarian crises and face multiple sexual and reproductive health (SRH) challenges in these contexts. There are an estimated 32 million women and 
girls of reproductive age (15-49 years) living in humanitarian crisis situations, all of whom need SRH information and services (2).

Reproductive health $(\mathrm{RH})$ service of female refugees is more vulnerable to poor utilization and outcomes of RH such as high-risk sexual behaviors, lack of contraception use, unwanted pregnancy, STI including HIV/AIDS. Women face high maternal mortality, unmet need for family planning, complications following unsafe abortion and gender-based violence (3). Humanitarian crises can increase the risk of poor RH outcomes due to reduced access to services and supplies, damaged health facilities and increased exposure to sexual violence among other factors(4).

There have been improvements in the availability of MISP RH service to people in refugee settings, but has shown underutilization of the services which exposed them to negative RH outcomes (5-9). The level of MISP RH utilizations by refugees is different among different settings. In the Sri Lanka crisis setting where FP utilization was found 50\%(10).In turkey FP utilized by Syrian refugee women was found to be $47 \%(11)$ and for the Thailand-Myanmar border refugees, the contraceptive uptake was $21 \%$ (12). In most Sub-Saharan African conflict sites MISP RH utilizations indicators such as contraceptive prevalence rate are far lower than in refugees of other areas. Contraceptive utilization of refugees in the Central African Republic, Democratic Republic of Congo and Sudan were under $10 \%$ (7\%, $4 \%$, and $7 \%)$ respectively(13). In Maitsebri primary hospital in Tselemty district from the total abortion care service given in 2018 161(80\%) were from Adiharush refugee which may indicate low utilization of MISP for RH in the refugee camp (14).

Low utilization of MISP RH service put refugee at greater risk of negative $\mathrm{RH}$ outcome (15).In humanitarian settings in Lebanon and Iraq found low FP utilization resulted in high prevalence of unwanted pregnancy $57.5 \%$ with $3.9 \%$ induced abortion (16)and was contributed to unsafe abortion, a major maternal death and disability (17). Prevalence of postnatal depression amongst un planed pregnant migrant women was reported as $11.2-60 \%$ and antenatal depression 12-45\% (18). In 2015, 61 $\%$ of maternal deaths worldwide occurred in 35 countries experiencing humanitarian crises with low utilization of MISP RH service of unplanned pregnancy $(4,16)$.Some of the possible causes of underutilization MISP RH service are; low information dissemination about availability of service, low demand for services(18), Unaware of the locations and presence for service (19).

Despite increased attention to MISP RH service provision in humanitarian crises settings, the evidence based information on utilization is still very limited. More implementation research is required to identify factors to increase utilization of MISP services in diverse humanitarian crises settings and populations(20). To the level of our knowledge there is no research that has assessed the factors affecting MISP RH service utilization in the female Eritrean Adiharush refugees' camp in Tselemty district of Tigray, Ethiopia. Though there are some similar studies elsewhere on MISP RH utilization, they may not reveal the gap of this refugee; because results by setting play an important role as they may not be generalized on to the other due to the differences between the settings. Therefore, assessment of the practices and factors associated with availability and implementation of the MISP for reproductive health 
in the Eritrean refugee camp, Northwestern zone of Tigray, Ethiopia would be help full in understanding the context so as to prevent morbidity and mortality of refugees in crisis.

\section{Materials And Methods}

\section{Study design and setting}

We conducted an Institution based cross sectional study to assess the minimum initial service package of reproductive health service utilization in Adiharush Eritrean refugee camp. The camp is found in Tselemty district, Northwestern zone of Tigray, Ethiopia. This refugee camp is located $1200 \mathrm{~km}$ far from Addis Ababa the capital city of Ethiopia and $400 \mathrm{~km}$ from Mekelle city the capital of Tigray. According to ARRA and Tselemty district health officethis refugee camp serves for around 26,234 refugees with 30 average daily new arrivals. It has one health center that provides SRH services like family planning, GBV service, counseling and testing of HIV/AIDS, maternal and child health service.

\section{Population}

The study population was all reproductive age group (15-49) of the Eritrean refugees who arrived to the camp during the data collection period, while the sample population was systematically selected female reproductive age group (15-49). The sample size was calculated using a single population proportion formula for surveys and it was found to be 422 .

\section{Sampling techniques and Procedure}

Participants were selected by using systematic random sampling method using the existing list of all individuals (obtained from ARAA registration books of refugees) as a sampling frame which were 1225 female reproductive age groups (15-49 yrs). All the reproductive women Eritrea refugees arrived to Adiharush Eritrean refugee camp was divided by the total sample size (422) to obtain the sampling interval which was three. A random number was picked as the starting point and then every three individuals who met the inclusion criteria were interviewed at their tent.

\section{Variables}

The outcome variable was Minimum initial service package for reproductive health utilization and the independent variables were Socio demographic variables, Health facility service related variables, Medical Supplies, Health education, availability of health service, family and peer pressure, residency, length of stay in refugee camp, Behavioral, Partner and family factors. Family pressure, partner pressure, residency of home country, level of exposure to RH service utilization in their home country, duration of stay in refugee and past experience of $\mathrm{RH}$ service utilization.

\section{Operational definition}


MISP for RH utilization is defined as: if a participant utilized the RH services (FP, GBV, and prevention of STI including HIV/AIDS) in Adiharish refugee camp.

FP service utilization was defined as ever use of any modern contraceptives while they were in Adiharush Eritrean refugee camp.

GBV service Utilization defined as ever use of counseling and youth friendly service to prevent sexual violence and use of service to assist post violated survivors while they were in Adiharush Eritrean refugee camp.

Prevention of STI Including HIV/AIDS transmission service utilization was defined as ever use of STI including HIV/AIDS transmission prevention methods, abstinence, condom use or one to one with partner while they were in Adiharush Eritrean refugee camp.

\section{Data Collection tool and technique}

The questionnaire was developed after reading different literature related to the topic. Thetool was structured and pretested and translated to the local language. It has an introduction and informed consent, socio demographic, behavioral factors and health service related factors which was designed to assessing factors and MISP RH utilizations by the refugees.

\section{Data analysis}

Each questionnaire collected from the field was checked for completeness, missed values and unlikely responses and manually cleaned. Then, data were coded and entered to a computer using Epi-Info version 7.1.1.4 then exported to SPSS version 20 for analysis. The data were crosschecked for consistency and accuracy. Descriptions of the main findings were done using frequencies, percentages, and summary statistics of the date. Binary Logistic Regression Model was fitted to assess factors associated MISP RH utilization. Those variables with $p$-value $\leq 0.25$ in the bivariate were entered to multivariable model. Before inclusion of predictors to the final logistic regression model, multi collinearly was checked using Variance Inflation Factor (VIF). The goodness of fit of the final logistic regression model was tested using Homer Lemeshow test and the $p$ value was 0.16 . Adjusted Odds Ratio and $95 \%$ confidence interval was reported.

\section{Ethical Consideration}

Ethical clearance was obtained from Institutional Review Board of Mekelle University College of CHS. Permission letter was also secured from Tigray Regional Health Bureau. Informed verbal consent was obtained from the sampled individuals and health center. The respondents' were also informed that they 
have full right to withdraw or refuse at any time from the process. Confidentiality of information given by each respondent has kept properly.

\section{Results}

Socio demographic characteristics of participants

In this study 412 women's were interviewed with a $98 \%$ response rate. The median age was 22(IQR, 8) years. More than half $245(59.5 \%)$ of the participants were single in their marital status. Majority of the participants 351 (84.1\%) have radio or television currently and 377 (91.5\%) were orthodox Christian religion (Table-1).

Table 1: socio-demographic characteristics of participants on MISP of RH utilization in Eritrean refugee camp, Tigray, 2019 
Variable

Category
MISP RH service utilization $(n=412)$.

Yes $(n, \%)) \quad$ No $(n, \%) \quad$ Total $(n, \%)$

Age category in year

Age category in year

$15-24$

25-34

$35-49$

Educational level

Marital status$$
\text { (1) }
$$

Occupation

\begin{tabular}{lllll}
\hline Occupation & housewife & $67(16.3)$ & $75(18.2)$ & $142(34.6)$ \\
\hline Student & $54(13.1)$ & $114(26.7)$ & $168(40.8)$ \\
\hline Other * & $35(8.5)$ & $67(16.3)$ & $102(24.6)$ \\
\hline Orthodox & $138(33.5)$ & $239(58)$ & $377(91.5)$ \\
\hline Other ** & $16(3.9)$ & $19(4.6)$ & $35(8.5)$ \\
\hline family size & $1-3$ family & $53(12.9)$ & $79(19.2)$ & $132(32)$ \\
\hline $4-5$ family & $41(10)$ & $83(20.1)$ & $124(30)$ \\
\cline { 2 - 4 } & $6-7$ family & $35(8.5)$ & $58(14)$ & $93(22.5)$ \\
\cline { 2 - 5 } & 8 and above & $24(5.8)$ & $36(8.7)$ & $60(14.5)$ \\
\hline Residence of home country & Rural & $78(18.9)$ & $177(43)$ & $255(61.9)$ \\
\cline { 2 - 5 } & Urban & $76(18.4)$ & $81(19.7)$ & $157(38.1)$
\end{tabular}

*(farmer, government and private employment) $*$ * (Muslim, catholic, and protestant)

More than half 214 (52\%) of the study participants had history of exposure to health education on reproductive health services. Of the total refugees 142 (34.5\%) of women stayed for one month in the refugee camp, while 111 (26.9\%) stayed for two months, and the rest for three months.

\section{Factors associated with MISP utilization for RH service}

We found that factors like age, residence in-home country, obtaining health education on reproductive health, residence period in the camp, marital status, and availability of medical supply were associated 
with utilization of MISP for RH service in the bivariate analysis. Moreover, women whose age was 25-34 years and 35-49 years were about two times more likely to utilize MISP for reproductive health service than the age group of 15-24 years. Those study participants who came from urban area of their home country were two times more likely utilize MISP service of reproductive health than those who came from rural area. Women who stayed for three month in the refugee camp were about 1.7 times more likely to utilize the service. Women who received health education on reproductive service in the refugee camp were 2.3 times more likely to utilize the MISP of reproductive service than their counterparts (Table 2).

Table 2: Factors associated with MISP utilization for RH service among reproductive age Women of Eritrean refugees at Adiharush Eritrean refugee camp, Tselemty, Tigray, Ethiopia, 2019 


\begin{tabular}{|c|c|c|c|c|c|}
\hline \multirow[t]{2}{*}{ Variable } & \multirow[t]{2}{*}{ Category } & \multicolumn{2}{|c|}{ MISP for RH Utilization } & \multirow{2}{*}{$\begin{array}{l}\mathrm{COR}(95 \% \\
\mathrm{Cl})\end{array}$} & \multirow{2}{*}{$\begin{array}{l}\text { AOR }(95 \% \\
\mathrm{Cl})\end{array}$} \\
\hline & & Yes $(n, \%)$ & No $(n, \%)$ & & \\
\hline \multirow[t]{3}{*}{ Age category in years } & $15-24$ & 79 (19.2) & $\begin{array}{l}182 \\
(44.2)\end{array}$ & 1.00 & 1.00 \\
\hline & $25-34$ & $49(11.9)$ & $52(12.6)$ & $\begin{array}{l}2.17(1.36- \\
3.48)^{\star}\end{array}$ & $\begin{array}{l}1.86(1.14 \\
3.04)^{\star \star}\end{array}$ \\
\hline & $35-49$ & $26(6.3)$ & $24(5.8)$ & $\begin{array}{l}2.5(1.35- \\
4.61)^{*}\end{array}$ & $\begin{array}{l}2.57(1.36 \\
4.88)^{\star \star}\end{array}$ \\
\hline \multirow[t]{2}{*}{ Residence } & Rural & 78 (18.9) & $177(43)$ & 1.00 & 1.00 \\
\hline & Urban & $76(18.4)$ & 81(19.7) & $\begin{array}{l}2.13(1.41- \\
3.21)^{\star}\end{array}$ & $\begin{array}{l}1.99(1.3- \\
3.04)^{\star \star}\end{array}$ \\
\hline \multirow[t]{3}{*}{$\begin{array}{l}\text { Duration of stay in the refugee } \\
\text { camp }\end{array}$} & $\begin{array}{l}\text { One } \\
\text { month }\end{array}$ & $40(9.7)$ & $102(24.8)$ & 1.00 & 1.00 \\
\hline & $\begin{array}{l}\text { Two } \\
\text { month }\end{array}$ & $44(10.7)$ & $67(16.3)$ & $\begin{array}{l}1.68(0.99- \\
2.84)^{\star}\end{array}$ & $\begin{array}{l}1.5(0.87- \\
2.62)\end{array}$ \\
\hline & $\begin{array}{l}\text { Three } \\
\text { month }\end{array}$ & 70(17) & $89(21.6)$ & $\begin{array}{l}2.01(1.24- \\
3.25)^{\star}\end{array}$ & $\begin{array}{l}1.67(1.01- \\
2.8)^{\star \star}\end{array}$ \\
\hline \multirow[t]{2}{*}{$\begin{array}{l}\mathrm{HE} \text { on } \mathrm{RH} \text { service in the } \\
\text { refugee camp }\end{array}$} & Yes & $101(24.5)$ & $113(27.4)$ & $\begin{array}{l}2.44(1.62- \\
3.7)^{\star}\end{array}$ & $\begin{array}{l}2.32(1.51- \\
3.56)^{\star \star}\end{array}$ \\
\hline & No & $53(12.9)$ & $145(35.2)$ & 1.00 & 1.00 \\
\hline \multirow[t]{2}{*}{ Medical supply problem } & Yes & $6(1.5)$ & $17(4.1)$ & $\begin{array}{l}0.56(0.11- \\
1.01)\end{array}$ & $\begin{array}{l}0.33(0.11- \\
1.05)\end{array}$ \\
\hline & No & $150(36.4)$ & 239(58) & 1.00 & 1.00 \\
\hline
\end{tabular}

\section{${ }^{*}$ p-value $<0.25, * *$ p-value $<0.05$}

\section{Discussion}

In this study, around 38\% of reproductive age women utilized MISP in reproductive health in the Eritrean refugee camp. Factors like age, residence in home country, history of obtaining health education on reproductive health, and stay period in the refugee camp were the factors associated with utilization of MISP for reproductive health.

The utilization of MISP for reproductive health was high compared to study findings in a systematic review of sexual and reproductive health among refugee women in Africa (16.7\%), Study in Somalia Hargeisa refugee camp (7\%) and study in Tanzania refugee camp $(9.2 \%)(7,15,27)$. This difference of RH utilization could be due to differences in facility supply, socioeconomic and demographic background of 
migrants, health education given about MISP RH service utilization, no language barrier because of the migrant's language is similar to the host community language.

Health education about reproductive health services can increase utilization of MISP of reproductive health. The result of this study showed that women's who obtain health education of reproductive health on the refugee camp were two times more likely to utilize the MISP of reproductive health than the counterpart. This study was similar with study conducted on systematic review based in low and middle income countries, Guinea refugees and Syrian Refugee $(20,23,24)$. This could be due to the fact that discussion of reproductive health services with population allows reproductive age group women to exchange information, experiences, and build comprehensive knowledge about $\mathrm{RH}$. This could be due to the evidence that health education increased different reproductive health service utilization in different part of the globe in refugee camps $(20,23,24)$.

Age has an effect on utilization of MISP for reproductive health service. This study showed that Women whose age 25-34 years and 35-49 years were about two times more likely utilize to MISP reproductive health service than in the age group of 15-24 years. This result is consistent with the study conducted in Guinea refugees (23). This might be due to the fact that youths were not more concerned about their reproductive and sexual health due to different reasons like shyness, bad behavioral activities and consequently results in low reproductive health service utilization. This could be also due to shortage of health education on reproductive health to those youth comparing to the adult one in this study. But this result is different from the study conducted in Nepal refugees and Gulu district Uganda refugees $(25,26)$. This difference may be due to difference in the community. Because in our case most of the participants were come to the refugee due to bad political issue but in Gulu and Nepal the participant were came due to current war. Also, the reason could be due to socio-cultural difference and in as age gets older may expose to some factors and learns lesson from previous event.

Duration of stay in the camp is affecting on the MISP. A woman's who stay for three month in the refugee camp was around 1.7 times more likely to utilize the service comparing the counterpart. This result is due the fact that those who stay more obtain service than those who stay less due to new arrival to refugees may unfamiliar to the new environmental, they are confused with the availability of reproductive health service in the refugee, limited information about reproductive health services.

Current place of residence has affecting on utilization of MISP for reproductive health. participants who came from urban area of their home country were two times more likely utilize on MISP service of reproductive health service than those who came from rural area. The finding is supported by the study conducted on systematic review on low and middle-income countries, Gulu district Uganda, Serial none $(6,20,25,26)$. This may be due to urban residents may have experience, awareness and knowledge with utilization of RH service in their home country than rural residents because of affordability of services, Availability of service, and the obtain more information with different media.

\section{Limitation Of The Study}


Since this study examines personal and sensitive issues, obtaining honest responses among reproductive age group women might have been difficult. Therefore this data might have been prone to Information bias (social desirability bias). To minimize this problem, discussion with participants during data collection was conducting to give their honest response by explain their confidentiality will be protected and the study will no effect on them.

\section{Conclusions}

The magnitude of MISP utilization on reproductive health service as compared to other refugee camps in Africa was relatively high. Age of the women, residence in the home country, and duration of stay in the camp and previous history of health education were factors affecting the utilization of MISP for reproductive health service in the refugee camp. To boost the utilization of services; provision of health education and counseling especially to youth on arrival to the camp would be very help full.

\section{Declarations}

\section{Abbreviations}

ARRA- Administration for Refugee and Returnee Affairs, AOR- Adjusted Odds Ratio, COR-Crude Odds Ratio, $\mathrm{Cl}$ - Confidence Interval, FP-Family planning, MISP-Minimum Initiation Service Package, $\mathrm{RH}$ Reproductive Health, SRH- sexual and Reproductive health, STI-Sexually Transmitted disease, VIFVariance Inflation Factor.

\section{Ethical approval and consent to participant}

Ethical clearance was obtained from the institutional review board of Mekelle University, College of health sciences and supportive letter was obtained from Tigray Regional Health Bureau to the study area. Participants were consented verbally. Confidentiality was maintained by not having identifying data on the questionnaire (i.e. anonymous). The data was not used for anything outside the study.

\section{Consent for publication}

Not applicable

\section{Availability of data and materials}

Data are available from the corresponding author on reasonable requests

\section{Competing interest}

The authors declare that they have no competing of interest among themselves. 


\section{Funding}

The study was funded by Mekelle University. The organization funded the activities related to questionnaire printing, data collection, supervision, report printing, and transportation.

\section{Author contribution}

ATH participated from conception, design, acquisition, analysis, and interpretation of data; ABK was involved from design, interpretation, preparation and revision of the manuscript. AT contributed in designing, data analysis, drafting and revising the manuscript.

\section{Acknowledgments}

We would like to thanks to Mekelle University for funding us to undertake this research. We are grateful to Adi Harish refugee camp staffs for giving us the needed data. We would also like to thank all the data collectors, supervisors, and study participants.

\section{References}

Feresu S, Smith L. Knowledge, attitudes, and beliefs about HIV/AIDS of Sudanese and Bantu Somali immigrant women living in Omaha, Nebraska. Open Journal of Preventive Medicine. 2013;3(1):720-6.

State of world population. New York: United Nations Population Fund, 2015

Austin J, Guy S, Lee-Jones L, McGinn T, Schlecht J. Reproductive health: a right for refugees and internally displaced persons. Rep heal matters. 2008;16(31):10-21.

Lisam S. Minimum initial service package (MISP) for sexual and reproductive health in disasters. J Evid Based Med 2014;7:245-8.

Beek KM. A system of influence: Identifying and addressing factors which determine the transfer of training on sexual and reproductive health in humanitarian settings 2016.

Casey S, Larsen M, McGinn T, Sartie M, Dauda M, Lahai P. Changes in HIV/AIDS/STI knowledge, attitudes, and behaviours among the youth in Port Loko, Sierra Leone. Global public health. 2006;1(3):249-63.

Ivanova $\mathrm{O}$, Rai M, Kemigisha E. A systematic review of sexual and reproductive health knowledge, experiences and access to services among Refugee, migrant and displaced girls and young women in Africa. International journal of environmental research and public health. 2018;15(8):1583.

Cherri Z, Gil Cuesta J, Rodriguez-Llanes J, Guha-Sapir D. Early marriage and barriers to contraception among Syrian refugee women in Lebanon: a qualitative study. In j envi re and pub heal. 2017;14(8):836. 
Metusela C, Ussher J, Perz J, Hawkey A, Morrow M, Narchal R, et al. “In My Culture, We Don't Know Anything About That": Sexual and Reproductive Health of Migrant and Refugee Women. In j behav med. 2017;24(6):836-45.

McGinn T. Barriers to reproductive health and access to other medical services in situations of conflict and migration. Wom, migration, and conflict: Springer; 2009. p. 129-43.

Alan Dikmen H, Cankaya S, Dereli Yilmaz S. The attitudes of refugee women in Turkey towards family planning. Pub Heal Nur. 2019;36(1):45-52.

Salisbury P, Hall L, Kulkus S, Paw MK, Tun NW, Min AM, et al. Family planning knowledge, attitudes and practices in refugee and migrant pregnant and post-partum women on the Thailand-Myanmar border-a mixed methods study. Rep heal. 2016;13(1):94.

Ferguson A, Shannon K, Butler J, Goldenberg SM. A comprehensive review of HIV/STI prevention and sexual and reproductive health services among sex Workers in Conflict-Affected Settings: call for an evidence-and rights-based approach in the humanitarian response. Conf and heal. 2017;11(1):25.

Annual report on RH activities of maitsebiry primary hospital 2018.

Mengesha ZB, Perz J, Dune T, Ussher J. Refugee and migrant women's engagement with sexual and reproductive health care in Australia: A socio-ecological analysis of heal care prof perspectives. PloS one. 2017;12(7):e0181421.

Balinska MA, Nesbitt R, Ghantous Z, Ciglenecki I, Staderini N. Reproductive health in humanitarian settings in Lebanon and Iraq: results from four cross-sectional studies, 2014-2015. Conf and Heal. $2019 ; 13(1): 24$.

Tousaw E, La RK, Arnott G, Chinthakanan O, Foster AM. "Without this program, women can lose their lives": migrant women's experiences with the Safe Abortion Referral Programme in Chiang Mai, Thailand. Rep heal matters. 2017;25(51):58-68.

Heslehurst N, Brown H, Pemu A, Coleman H, Rankin J. Perinatal health outcomes and care among asylum seekers and refugees: a systematic review of systematic reviews. BMC med. 2018;16(1):89.

Fellmeth G, Paw MK, Wiladphaingern J, Charunwatthana P, Nosten F, McGready R. Maternal suicide risk among refugees and migrants. In J of Gyn and Obs. 2016;134(2).

Singh NS, Smith J, Aryasinghe S, Khosla R, Say L, Blanchet K. Evaluating the effectiveness of sexual and reproductive health services during humanitarian crises: A systematic review. PloS one. 2018;13(7):e0199300.

Herman L, Isaac E, Mary N, Richard M. Determinants of contraceptive utilisationamongst teenagemothers: a case-control study in kyangwali refugee settlement (Uganda).IntJCurr Adv Res. 
2015;4(8):243-57.

Tran N-T, Dawson A, Meyers J, Krause S, Hickling C, Group I-AW. Developing institutional capacity for reproductive health in humanitarian settings: a descriptive study. PLoS One. 2015;10(9):e0137412.

Woodward A, Howard N, Souare Y, Kollie S, von Roenne A, Borchert M. Reproductive health for refugees by refugees in Guinea IV: Pe educ and HIV knowledge, attitudes, and reported practices. Confl and heal. 2011;5(1):10.

Salemi C, Bowman J, Compton J, editors. Services for Syrian Refugee Children and Youth in Jordan: Forced Displacement, Foreign Aid, and Vulnerability. Economic Research Forum Working Paper Series; 2018.

Chaudhary P, Vallese G, Thapa M, Alvarez VB, Pradhan LM, Bajracharya K, et al. Humanitarian response to reproductive and sexual health needs in a disaster: the Nepal Earthquake 2015 case study. Rep heal matt. 2017;25(51):25-39.

Orach CG, Otim G, Aporomon JF, Amone R, Okello SA, Odongkara B, et al. Perceptions, attitude and use of family planning services in post conflict Gulu district, northern Uganda. Confl and heal. 2015;9(1):24.

Millington K. Fam Planning for Refugees in Camps in Tanzania. 2019 